\title{
Shiga toxin-producing Escherichia coli in British Columbia, 2011-2017: Analysis to inform exclusion guidelines
}

\author{
K Noftall ${ }^{1,2}$, M Taylor ${ }^{1}$, L Hoang ${ }^{3,4}$, E Galanis ${ }^{1,2 *}$
}

\begin{abstract}
Background: Shiga toxin-producing Escherichia coli (STEC) can cause severe illness including bloody diarrhea and hemolytic-uremic syndrome (HUS) through the production of Shiga toxins 1 (Stx1) and 2 (Stx2). E. coli O157:H7 was the most common serotype detected in the 1980s to 1990s, but improvements in laboratory methods have led to increased detection of non-O157 STEC. Non-O157 STEC producing only Stx 1 tend to cause milder clinical illness. Exclusion guidelines restrict return to high-risk work or settings for STEC cases, but most do not differentiate between STEC serogroups and Stx type.
\end{abstract}

Objective: To analyze British Columbia (BC) laboratory and surveillance data to inform the $B C$ STEC exclusion guideline.

Methods: For all STEC cases reported in BC in 2011-2017, laboratory and epidemiological data were obtained through provincial laboratory and reportable disease electronic systems, respectively. Incidence was measured for all STEC combined as well as by serogroup.

Associations were measured between serogroups, Stx types and clinical outcomes.

Results: Over the seven year period, 984 cases of STEC were reported. A decrease in 0157 incidence was observed, while non-O157 rates increased. The $\mathrm{O} 157$ serogroup was significantly associated with Stx2. Significant associations were observed between Stx2 and bloody diarrhea, hospitalization and HUS.

Conclusion: The epidemiology of STEC has changed in BC as laboratories increasingly distinguish between $\mathrm{O} 157$ and non-O157 cases and identify Stx type. It appears that non-O157 cases with Stx1 are less severe than 0157 cases with Stx2. The BC STEC exclusion guidelines were updated as a result of this analysis.
This work is licensed under a Creative Commons Attribution 4.0 International License.

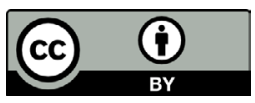

Affiliations

${ }^{1}$ BC Centre for Disease Control, Vancouver, BC

2 School of Population and Public Health, University of British Columbia, Vancouver, BC

${ }^{3}$ BC Centre for Disease Control Public Health Laboratory, Vancouver, BC

${ }^{4}$ Department of Pathology and Laboratory Medicine, Faculty of Medicine, University of British

Columbia, Vancouver, BC

\section{${ }^{\star}$ Correspondence:}

eleni.galanis@bccdc.ca

Suggested citation: Noftall K, Taylor M, Hoang L, Galanis E. Shiga toxin-producing Escherichia coli in British Columbia, 2011-2017: Analysis to inform exclusion guidelines. Can Commun Dis Rep 2019;45(9):238-43.

https://doi.org/10.14745/ccdr.v45i09a03

Keywords: Shiga toxin, Escherichia coli, guidelines, surveillance, STEC

\section{Introduction}

Escherichia coli has long been known to be part of the normal flora of the gastrointestinal tract. Some E. coli strains evolved to cause human illness by acquiring virulence factors such as Shiga toxin. These organisms have been renamed Shiga toxin-producing E. coli (STEC) (1). The best known STEC serotype, E. coli O157:H7, was first detected in the 1980s in patients with serious illnesses including hemorrhagic colitis and hemolytic-uremic syndrome (HUS) $(2,3)$. In the 1990s, once laboratories started to routinely test for E. coli O157:H7, it became recognized as the cause of large and serious outbreaks mainly associated with undercooked beef $(4,5)$.

In the early 2000 s, laboratories began to implement methods to detect other STEC serotypes $(6,7)$. This led to the recognition that non-O157 STEC can contaminate a wide variety of sources and cause large outbreaks $(8,9)$. However, non-O157 STEC remain underreported because many frontline laboratories 
do not yet routinely test for them (10). Nonetheless, by 2016, approximately $35 \%$ of all STEC infections reported to the Canadian National Enteric Surveillance Program were caused by non-O157 serotypes (11).

STEC stx genes produce Shiga toxins 1 (Stx 1$)$ and 2 (Stx2). Stx2 is associated with severe illness and HUS (8,12-20). Furthermore, Stx2 is associated with STEC 0157, which explains this serogroup's higher pathogenicity $(17,21,22)$. A polymerase chain reaction (PCR) test was implemented at the British Columbia Centre for Disease Control Public Health Laboratory (BCCDC $\mathrm{PHL}$ ) in 2013 to detect and differentiate between stx 1 and 2 genes.

In order to protect the population from severe infection, most public health authorities exclude people infected with STEC from working or attending certain high-risk settings $(23,24)$. For example, the 2006 BCCDC guidelines stated that a person diagnosed with STEC who works as a food handler, health care worker or child care worker or who attends a child care facility should be excluded from that setting until they have provided two negative stool samples (25).

The increasing detection of non-O157 STEC and their association with Stx 1 and less severe disease led us to question the appropriateness of exclusion guidelines that do not differentiate between serogroups and Stx types. A review of existing guidelines demonstrated that four regions had recently updated their recommendations to stratify exclusion from workplaces and daycares by serogroup and Stx type (26-29).

The purpose of this work was to analyze British Columbia (BC) laboratory and surveillance data to inform the BC STEC exclusion guideline.

\section{Methods}

\section{Study sample}

This study included all confirmed cases of STEC who were $B C$ residents and reported in the provincial electronic public health information system between January 1, 2011 and December 31, 2017 (30). For these cases, all STEC culture, serogroup and PCR stx results were accessed from the BCCDC $\mathrm{PHL}$ information system.

\section{Laboratory data}

In BC, stool specimens may be processed at a private laboratory, hospital laboratory or the BCCDC PHL. At private and hospital laboratories, STEC are identified using culture or molecular methods. STEC isolates that are Stx positive or O157, as well as specimens that are visibly bloody or that came from a case diagnosed with HUS, are sent to the BCCDC PHL for further testing and serotyping. Until 2013, Stx was detected using a Vero cell assay at the BCCDC PHL; since 2013, stx 1 and 2 genes have been detected by PCR from stool samples and from suspected STEC isolates recovered from stx-positive stool samples from private and hospital laboratories. Positive stx isolates are serotyped for $\mathrm{O} 157$ antigen, $\mathrm{H} 7$ antigen and an O-Typer PCR covering the six most common serogroups seen in BC: O26, O45, 0103, 0111, 0121 and 0145. Any stx-positive isolate that cannot be serotyped is sent to the National Microbiology Laboratory for identification.

Variables included from BCCDC PHL data were Stx type and serogroup. If Vero cell assay was used, the Stx result was reported as positive; when PCR was performed, the stx gene was recorded. When multiple laboratory test results were available for individual cases, the most specific serotype result was included.

\section{Surveillance data}

STEC cases are reportable in BC and are interviewed by public health professionals using a standard surveillance form $(30,31)$. All health authorities report STEC cases provincially through the $\mathrm{BC}$ provincial electronic public health information system. Self-reported data on demographics, clinical symptoms, hospitalization and HUS status were extracted from this system. Laboratory data may also be entered into this system as part of routine surveillance by the health authority.

Hospitalization status and exclusion information were only available for cases from 2015-2017. Clinical data were available from four of five health authorities. Cases were considered to have a symptom or outcome if "yes" was recorded for that data field. If no laboratory results were available from BCCDC PHL, the laboratory information reported by the health authorities into the public health information system was used.

\section{Analysis}

BCCDC STEC surveillance data and BCCDC PHL STEC lab data from 2011 to 2017 were linked together by a common case identifier. Incidence rates were calculated using the BC population data (32). Differences in STEC incidence rates between females and males were conducted using the Wilcoxon rank sum test. Clinical information was compared by serogroups and by Stx type for all symptoms as well as for HUS and hospitalization using Fisher exact test. An alpha level of 0.05 was used for significance, and all statistical tests were conducted using R statistical computing program (33). When exclusion information was available, excluded cases were categorized by serogroup and Stx type. 


\section{Results}

Between 2011 and 2017, 984 cases of STEC were reported in BC, with an average of 141 cases per year (range: 108-184). The overall STEC incidence during this time period was 3.0 cases per 100,000. Outbreaks occurred in 2013, 2016 and 2017. There were more female $(57.4 \%)$ than male $(42.6 \%)$ cases, but there was no significant difference in rates by sex for all STEC cases or by serogroups (data not shown). The median age was 31 years (range <1-113), and the highest incidence was in 1-9 year olds at 4.9 cases per 100,000 .

In total, 58 serogroups were identified. Nearly $10 \%$ of samples were culture negative and stx positive only (Table 1). The six most common serogroups were O157, O121, O26, O103, O117 and 0111 . The most reported serogroup was 0157 for every year except 2017, when 0121 cases were more common.

Overall, 0157 rates have declined from 1.1 to 0.5 per 100,000 Table 1: Serogroup and Shiga toxin results for Shiga toxin-producing Escherichia coli cases, British Columbia, 2011-2017 ( $\mathrm{N}=984)$

\begin{tabular}{|l|r|r|}
\hline \multicolumn{1}{|c|}{ Serogroup } & N & \multicolumn{2}{|c|}{ (\%) } \\
\hline O157 & 369 & $(37.5)$ \\
\hline O121 & 102 & $(10.4)$ \\
\hline O26 & 86 & $(8.7)$ \\
\hline O103 & 44 & $(4.5)$ \\
\hline O117 & 38 & $(3.9)$ \\
\hline O111 & 34 & $(3.5)$ \\
\hline Other serogroups & 152 & $(15.4)$ \\
\hline Stx positive only & 93 & $(9.5)$ \\
\hline Unknown $^{\text {a }}$ & & 66 \\
\hline \multicolumn{1}{|c|}{ Shiga toxin } & & $(6.7)$ \\
\hline
\end{tabular}

\section{Shiga toxin}

$\mathbf{N}$

\begin{tabular}{|l|r|r|}
\hline Stx positive & 111 & $(11.3)$ \\
\hline Stx1 & 270 & $(27.4)$ \\
\hline Stx1 and Stx2 & 239 & $(24.3)$ \\
\hline Stx2 & 274 & (27.8) \\
\hline Stx unknown & 90 & $(9.1)$ \\
\hline
\end{tabular}

Abbreviations: Stx, Shiga toxin; Stx1, Shiga toxin 1; Stx2, Shiga toxin 2

a Cases where no laboratory results were available at the British Columbia Public Health Laboratory. Cases were reported solely by public health authorities

${ }^{b}$ Cases where Shiga toxin was detected by Vero cell assay and not a polymerase chain reaction (PCR)

reaction $(P C R)$
Includes cases reported solely by public health authorities $(N=81)$ and those reported by the Public Health Laboratory for which Stx type was not available for epidemiological analysis $(N=9)$

from 2011 to 2017 (Figure 1). Non-O157 rates have increased greatly from 0.6 to 2.4 per 100,000 between 2011 and 2017 .

The presence of Stx was confirmed in 894 cases (90.1\%; Table 1). For 111 cases (11.3\%), Stx was detected by Vero cell assay only, and specific Stx type was not available. Of the 783 cases where the stx gene was identified by PCR, 270 (34.5\%) were
Figure 1: Shiga toxin-producing Escherichia coli incidence by serogroup, British Columbia, 2011-2017 $(\mathrm{N}=984)$

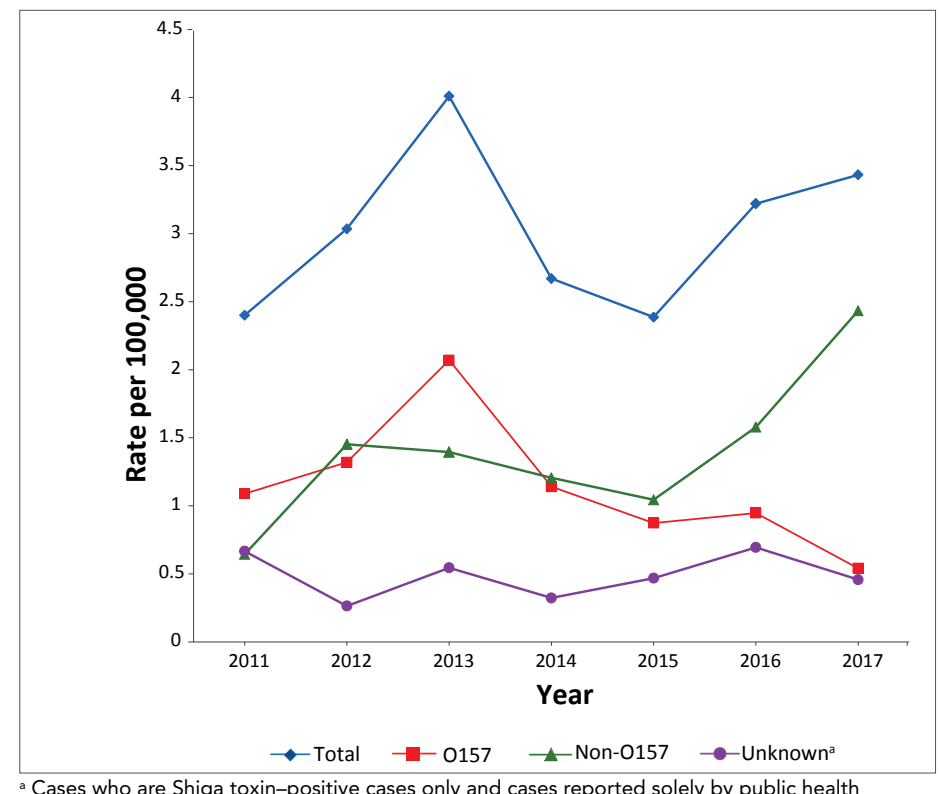

Cases who are Shiga toxin-positive cases only and cases reported solely by public health authorities without laboratory information from the Public Health Laboratory

positive for stx1 only, 274 (35.0\%) were positive for stx2 only, and 239 (30.5\%) were from STEC that contained both stx 1 and st $x 2$. Therefore, $65.5 \%$ of cases where the stx gene was detected tested positive for stx2 (alone or in combination). When both serogroup and stx gene were identified ( $N=711), 97.7 \%$ of 0157 STEC contained stx2 alone or in combination compared to $42.9 \%$ of non-O157 serogroups [odd ratio $(O R)=56.5 ; p \leq 0.001$ ].

Clinical information was available for 594 cases (60.4\%). The most commonly reported symptoms were diarrhea $(90.2 \%)$, abdominal discomfort (70.2\%), bloody diarrhea (56.6\%), vomiting (24.6\%), fever (21.4\%) and fatigue (13.6\%). Eighteen cases $(3.0 \%)$ were recorded as having HUS at the time of the public health interview. Cases with $E$. coli 0157 infection were more likely to have bloody diarrhea, fatigue and hospitalization than non-O157 cases (Table 2). Although a larger proportion of 0157 cases $(4.9 \%)$ had HUS than non-O157 cases (1.9\%), this was not statistically significant. Cases with stx2 were significantly more likely to have bloody diarrhea and HUS and be admitted to hospital than cases with stx1 only (Table 2).

Exclusion information was available for 276 (64\%) cases between 2015 and 2017. Forty-three cases (16\%) had been excluded from high-risk occupations or settings. Ten of the cases were positive for 0157 (23.3\%), 28 were positive for a non-O157 STEC (65.1\%) and five had an unknown serogroup (11.6\%). Twenty-one cases (48.8\%) had STEC with stx2 present, 20 (46.5\%) had STEC with stx1 only and two (4.7\%) had STEC with indeterminate stx PCR results. All 0157 STEC cases were stx2 positive. 
Table 2: Clinical severity by Escherichia coli serogroup and Shiga toxin type among Shiga toxin-producing Escherichia coli cases, British Columbia, 2011-2017 ${ }^{\text {a }}(\mathrm{N}=594)$

\begin{tabular}{|c|c|c|c|c|c|c|c|c|c|c|}
\hline \multirow{3}{*}{$\begin{array}{l}\text { Clinical } \\
\text { outcome }\end{array}$} & \multicolumn{5}{|c|}{ Serogroup } & \multicolumn{5}{|c|}{ Shiga toxin type } \\
\hline & \multicolumn{2}{|c|}{0157} & \multicolumn{2}{|c|}{ Non-0157 } & \multirow{2}{*}{$p$-value } & \multicolumn{2}{|c|}{ Stx2 present } & \multicolumn{2}{|c|}{ Stx1 only } & \multirow[b]{2}{*}{ p-value } \\
\hline & $\mathbf{N}$ & $(\%)$ & $\mathbf{N}$ & (\%) & & $\mathbf{N}$ & $(\%)$ & $\mathbf{N}$ & (\%) & \\
\hline $\begin{array}{l}\text { Abdominal } \\
\text { discomfort }\end{array}$ & 177 & $(72.5)$ & 189 & (70.3) & 0.625 & 262 & (73.8) & 106 & $(69.3)$ & 0.330 \\
\hline Diarrhea & 221 & (90.5) & 250 & (92.9) & 0.339 & 321 & (90.4) & 138 & $(90.2)$ & 1.000 \\
\hline $\begin{array}{l}\text { Bloody } \\
\text { diarrhea }\end{array}$ & 168 & (68.9) & 136 & $(50.6)$ & $<0.001$ & 231 & (65.1) & 69 & $(45.1)$ & $<0.001$ \\
\hline Fatigue & 46 & (18.9) & 25 & (9.3) & 0.002 & 53 & (14.9) & 17 & (11.1) & 0.326 \\
\hline Fever & 57 & (23.4) & 50 & $(18.6)$ & 0.193 & 78 & (22.0) & 27 & $(17.6)$ & 0.285 \\
\hline Vomiting & 63 & $(25.8)$ & 64 & (23.8) & 0.610 & 85 & (23.9) & 34 & (22.2) & 0.733 \\
\hline HUS & 12 & (4.9) & 5 & (1.9) & 0.081 & 15 & $(4.2)$ & 1 & $(0.7)$ & 0.048 \\
\hline Hospitalised $^{b}$ & 29 & (35.4) & 25 & (16.1) & 0.001 & 52 & (31.7) & 13 & (13.8) & 0.002 \\
\hline
\end{tabular}

Abbreviations: HUS, hemolytic-uremic syndrome; Stx1, Shiga toxin 1; Stx2, Shiga toxin 2

a Information from cases in four of five health authorities; only cases with known serogroup or Shiga toxin type included

${ }^{b}$ Hospitalization status only available for cases from 2015 to 2017

\section{Discussion}

Analysis of laboratory and surveillance data in BC showed a shifting pattern in the distribution of STEC serogroups between 2011 and 2017 with the incidence of 0157 declining and the incidence of non-O157 increasing, particularly between 2015 and 2017. This is consistent with the decline in the incidence of 0157 that has been observed across Canada (34) and the United States $(6,8,22,35,36)$. The decrease in 0157 in Canada may be due to sanitary improvements in beef processing as well as better food safety education to consumers (34). The increase in incidence of non-O157 in BC and elsewhere may be due to the increase in use of laboratory methods enabling the detection of non-O157 strains $(6,36)$.

A strong association was seen between the 0157 serogroup and Stx 2 with nearly $98 \%$ of 0157 cases being positive for Stx2, consistent with earlier studies $(15,16,21,22)$. Also observed were the associations between 0157 STEC cases and severe clinical outcomes such as hemorrhagic colitis and hospitalization $(17,22,37)$. There was a significant relationship between stx2 and HUS, bloody diarrhea and hospitalization. Stx variants (e.g. stx2d), which have been shown to be more specific predictors of severe illness than Stx type, are not yet available in BC $(13,15,16,18-20,38)$.

This analysis was conducted to inform the BC STEC exclusion guideline. Consistent with our findings and other recently updated guidelines stratifying exclusion by serogroup and Stx (26-29), the new BC guideline now reflects the evidence that STEC producing Stx1 only leads to less severe illness (39). Based on the revised guideline whereby non-0157 stx 1 only cases without severe clinical symptoms could return to high-risk work or settings when symptom-free, 16 excluded cases (37.2\%) between 2015 and 2017 would have had their exclusion lifted earlier. Assuming the median duration of symptoms is seven days and the median duration of shedding is 20 days $(40,41)$, this could have resulted in avoiding up to 208 days of lost productivity for these individuals.

This study has a few limitations. Laboratory practice for Stx detection changed during the study period, so we were unable to differentiate Stx types between 2011 and 2013. Symptoms were self-reported and only available for four of the five health authorities in the province. Despite this, the proportion of cases with symptoms was similar to that observed in other studies $(22,42)$. There is no reason to believe symptoms and outcomes for the same disease would be different for the one health authority from which these data were unavailable. The number of HUS cases was likely an underestimate given that HUS may not have developed at the time of the public health interview, which occurs one to two weeks after symptom onset (43). Nonetheless, a significant association with st 2 was observed, and this association may be even stronger with a higher number of HUS cases. Exclusion information was not available prior to 2015 and was not always recorded after that. Because of this, only a descriptive analysis was performed for excluded cases.

An evaluation of this guideline change in $B C$ is recommended to ensure its impact was as initially intended. Furthermore, the guideline will need to be reviewed as laboratory methods for 
STEC and Stx detection progress, such as by testing for specific Stx variants.

\section{Conclusion}

Data from $B C$ is consistent with observations elsewhere that STEC bacteria cause a spectrum of illness and this is, at least in part, determined by Stx type. As a result of this analysis, the BC STEC exclusion guideline was updated in February 2019 to allow cases infected with non-O157 stx1 only STEC without severe clinical symptoms to return to high-risk settings when symptom-free.

\section{Authors' Statement}

$\mathrm{KN}$ - Analyzed the data and drafted the paper MT - Conceptualized the study, interpreted the data and revised the paper $\mathrm{LH}$ - Interpreted the data and revised the paper EG - Conceptualized the study, interpreted the data, drafted certain sections and revised the paper

\section{Conflict of interest}

None.

\section{Acknowledgements}

The authors are grateful to A Paccagnella and British Columbia Enteric Policy Group members (O Bitzikos, D Hoyano, M McKinley, S Mema, P Rydings, J Stone, D Tam) who contributed data or participated in the decision making about the ensuing guideline changes. The authors also want to acknowledge the editorial contributions of the Editor-in-Chief of the Canada Communicable Disease Report (CCDR).

\section{References}

1. Lim JY, Yoon J, Hovde CJ. A brief overview of Escherichia coli O157:H7 and its plasmid O157. J Microbiol Biotechnol 2010 Jan;20(1):5-14. PubMed

2. Riley LW, Remis RS, Helgerson SD, McGee HB, Wells JG, Davis BR, Hebert RJ, Olcott ES, Johnson LM, Hargrett NT, Blake PA, Cohen ML. Hemorrhagic colitis associated with a rare Escherichia coli serotype. N Engl J Med 1983 Mar;308(12):681-5. DOI PubMed

3. Karmali MA, Steele BT, Petric M, Lim C. Sporadic cases of haemolytic-uraemic syndrome associated with faecal cytotoxin and cytotoxin-producing Escherichia coli in stools. Lancet 1983 Mar;321(8325):619-20. DOI PubMed

4. Rangel JM, Sparling PH, Crowe C, Griffin PM, Swerdlow DL. Epidemiology of Escherichia coli O157:H7 outbreaks, United States, 1982-2002. Emerg Infect Dis 2005 Apr;11(4):603-9. DOI PubMed

5. Boyce TG, Pemberton AG, Wells JG, Griffin PM. Screening for Escherichia coli O157:H7--a nationwide survey of clinical laboratories. J Clin Microbiol 1995 Dec;33(12):3275-7. PubMed
6. Hughes JM, Wilson ME, Johnson KE, Thorpe CM, Sears CL. The emerging clinical importance of non-O157 Shiga toxin-producing Escherichia coli. Clin Infect Dis 2006 Dec;43(12):1587-95. DOI PubMed

7. Parsons BD, Zelyas N, Berenger BM, Chui L. Detection, characterization, and typing of Shiga toxin-producing Escherichia coli. Front Microbiol 2016 Apr;7:478. DOI PubMed

8. Luna-Gierke RE, Griffin PM, Gould LH, Herman K, Bopp CA, Strockbine N, Mody RK. Outbreaks of non-O157 Shiga toxin-producing Escherichia coli infection: USA. Epidemiol Infect 2014 Nov;142(11):2270-80. DOI PubMed

9. Morton V, Cheng JM, Sharma D, Kearney A. An outbreak of Shiga toxin-producing Escherichia coli O121 infections associated with flour-Canada, 2016-2017 ${ }^{\dagger}$. Can Commun Dis Rep 2017 Jul;43(7/8):154-5. DOI PubMed

10. Chui L, Christianson S, Alexander DC, Arseneau V, Bekal S, Berenger B, Chen Y, Davidson R, Farrell DJ, German GJ, Gilbert L, Hoang L, Johnson RP, MacKeen A, Maki A, Nadon C, Nickerson E, Peralta A, Arneson SR, Yu Y, Ziebell K. CPHLN recommendations for the laboratory detection of Shiga toxin-producing Escherichia coli (O157 and non-O157). Can Commun Dis Rep 2018 Nov;44(11):304-7. DOI PubMed

11. Government of Canada. National Enteric Surveillance Program (NESP): Annual summary 2016 including serotype and phage type tables for 2016, NESP AND NML. Ottawa (ON): Public Health Agency of Canada; 2018. http://publications.gc.ca/collections/ collection_2018/aspc-phac/HP37-15-2016-eng.pdf

12. Basu D, Li XP, Kahn JN, May KL, Kahn PC, Tumer NE. The A1 subunit of Shiga toxin 2 has higher affinity for ribosomes and higher catalytic activity than the A1 subunit of Shiga toxin 1. Infect Immun 2015 Oct;84(1):149-61. DOI PubMed

13. Bielaszewska M, Friedrich AW, Aldick T, Schürk-Bulgrin R, Karch $\mathrm{H}$. Shiga toxin activatable by intestinal mucus in Escherichia coli isolated from humans: predictor for a severe clinical outcome. Clin Infect Dis 2006 Nov;43(9):1160-7. DOI PubMed

14. Boerlin P, McEwen SA, Boerlin-Petzold F, Wilson JB, Johnson RP, Gyles CL. Associations between virulence factors of Shiga toxin-producing Escherichia coli and disease in humans. J Clin Microbiol 1999 Mar;37(3):497-503. PubMed

15. Brandal LT, Wester AL, Lange H, Løbersli I, Lindstedt BA, Vold L, Kapperud G. Shiga toxin-producing escherichia coli infections in Norway, 1992-2012: characterization of isolates and identification of risk factors for haemolytic uremic syndrome. BMC Infect Dis 2015 Aug;15:324. DOl PubMed

16. Eklund M, Leino K, Siitonen A. Clinical Escherichia coli strains carrying stx genes: stx variants and stx-positive virulence profiles. J Clin Microbiol 2002 Dec;40(12):4585-93. DOI PubMed

17. Ethelberg S, Olsen KE, Scheutz F, Jensen C, Schiellerup P, Enberg J, Petersen AM, Olesen B, Gerner-Smidt P, Mølbak K. Virulence factors for hemolytic uremic syndrome, Denmark. Emerg Infect Dis 2004 May; 10(5):842-7. DOI PubMed

18. Haugum K, Johansen J, Gabrielsen C, Brandal LT, Bergh K, Ussery DW, Drabløs F, Afset JE. Comparative genomics to delineate pathogenic potential in non-O157 Shiga toxin-producing Escherichia coli (STEC) from patients with and without haemolytic uremic syndrome (HUS) in Norway. PLoS One 2014 Oct;9(10):e111788. DOI PubMed 
19. Orth D, Grif K, Khan AB, Naim A, Dierich MP, Würzner R. The Shiga toxin genotype rather than the amount of Shiga toxin or the cytotoxicity of Shiga toxin in vitro correlates with the appearance of the hemolytic uremic syndrome. Diagn Microbiol Infect Dis 2007 Nov;59(3):235-42. DOl PubMed

20. Persson S, Olsen KE, Ethelberg S, Scheutz F. Subtyping method for Escherichia coli shiga toxin (verocytotoxin) 2 variants and correlations to clinical manifestations. J Clin Microbiol 2007 Jun;45(6):2020-4. DOI PubMed

21. Werber D, Fruth A, Buchholz U, Prager R, Kramer MH, Ammon $A$, Tschäpe $H$. Strong association between shiga toxin-producing Escherichia coli $\mathrm{O} 157$ and virulence genes stx2 and eae as possible explanation for predominance of serogroup $\mathrm{O} 157$ in patients with haemolytic uraemic syndrome. Eur J Clin Microbiol Infect Dis 2003 Dec;22(12):726-30. DOI PubMed

22. Hedican EB, Medus C, Besser JM, Juni BA, Koziol B, Taylor C, Smith KE. Characteristics of O157 versus non-O157 Shiga toxin-producing Escherichia coli infections in Minnesota, 2000-2006. Clin Infect Dis 2009 Aug;49(3):358-64. DOI PubMed

23. Heymann $\mathrm{DL}$, editor. Control of communicable diseases manual. 19th edition. Washington (DC): American Public Health Association; 2008.

24. MacDonald E, Dalane PK, Aavitsland P, Brandal LT, Wester AL, Vold L. Implications of screening and childcare exclusion policies for children with Shiga-toxin producing Escherichia coli infections: lessons learned from an outbreak in a daycare centre, Norway, 2012. BMC Infect Dis 2014 Dec;14:673. DOI PubMed

25. BC Centre for Disease Control. Communicable disease control enteric cases and their contacts: exclusion from high risk settings. Vancouver (BC): BCCDC; 2013 May. http://www.bccdc.ca/ resource-gallery/Documents/Guidelines\%20and\%20Forms/ Guidelines\%20and\%20Manuals/Epid/CD\%20Manual/ Chapter\%201\%20-\%20CDC/EntericCasesandtheirContacts_ May2013.pdf

26. Minnesota Department of Health. Specific disease exclusion guidelines for child care and preschool. 2019. St. Paul (MN): MDH; 2019 (Accessed 2019-06-18). https://www.health.state.mn.us/ diseases/foodborne/exclusions.html

27. Folkehelseinstituttet. [Follow-up of cases of Shiga toxin (Stx) producing Escherichia coli (STEC/EHEC) and hemolytic-uremic syndrome (HUS) in Norway]. Oslo: Norwegian Institute of Public Health; 2016. Norwegian (Accessed 2018-05-09). https://www. fhi.no/globalassets/dokumenterfiler/veiledere/oppfolging_av_ ehecpasienter_2016.pdf

28. Ministère de la santé et des services sociaux. Escherichia coli entérohémorrhagic (Gastroentérite À). Québec (QC): Ministère de la santé et des services sociaux; 2016 (Accessed 2018-05-10). http:// publications.msss.gouv.qc.ca/msss/fichiers/guide-garderie/ chap7-escheria-coli.pdf

29. Statens Serum Institut. [Hemolytic-uraemic syndrome]. Copenhagen: Statens Serum Institut; Danish (Accessed 2018-05-10). https://www. ssi.dk/sygdomme-beredskab-og-forskning/sygdomsleksikon/h/ haemolytisk-uraemisk-syndrom

30. BC Centre for Disease Control. E. coli. Vancouver (BC): BCCDC (Accessed 2018-06-08). http://www.bccdc.ca/health-professionals/ clinical-resources/case-definitions/e-coli

31. BC Centre for Disease Control. Shigatoxigenic E. coli case report form. Version date: 2018/06/22. Vancouver (BC): BCCDC; 2018. http://www.bccdc.ca/resource-gallery/Documents/ Guidelines\%20and\%20Forms/Forms/Epid/Enterics/VTEC_ FollowupForm.pdf
32. BCStats. Sub-provincial population projections - P.E.O.P.L.E. 2017 (Access 2018-06-08). https://www.bcstats.gov.bc.ca/apps/ PopulationProjections.aspx

33. R Core Team. R: A language and environment for statistical computing. Vienna, Austria: R Foundation for Statistical Computing; 2017.

34. Pollari F, Christidis T, Pintar KD, Nesbitt A, Farber J, Lavoie MC, Gill A, Kirsch P, Johnson RP. Evidence for the benefits of food chain interventions on E. coli 0157:H7/NM prevalence in retail ground beef and human disease incidence: A success story. Can J Public Health 2017 Apr;108(1):e71-8. DOI PubMed

35. Gould LH, on behalf of the STEC Clincal Laboratory Diagnostics Working Group. Update: recommendations for diagnosis of Shiga toxin-producing Escherichia coli infections by clinical laboratories. Clin Microbiol Newsl 2012;34(10):75-83. DOI

36. Marder EP, Griffin PM, Cieslak PR, Dunn J, Hurd S, Jervis R, Lathrop S, Muse A, Ryan P, Smith K, Tobin-D'Angelo M, Vugia DJ, Holt KG, Wolpert BJ, Tauxe R, Geissler AL. Preliminary incidence and trends of infections with pathogens transmitted commonly through food-Foodborne Diseases Active Surveillance Network, 10 U.S. Sites, 2006-2017. MMWR Morb Mortal Wkly Rep 2018 Mar;67(11):324-8. DOI PubMed

37. Wang X, Taylor M, Hoang L, Ekkert J, Nowakowski C, Stone J, Tone G, Trerise S, Paccagnella A, Wong T, Galanis E. Comparison of clinical and epidemiological features of Shiga toxin-producing Escherichia coli O157 and non-O157 infections in British Columbia, 2009 to 2011. Can J Infect Dis Med Microbiol 2013;24(4):e102-6. DOI PubMed

38. Friedrich AW, Bielaszewska M, Zhang WL, Pulz M, Kuczius T, Ammon A, Karch H. Escherichia coli harboring Shiga toxin 2 gene variants: frequency and association with clinical symptoms. J Infect Dis 2002 Jan;185(1):74-84. DOI PubMed

39. BC Centre for Disease Control. Communicable disease control enteric cases and their contacts: exclusion from high risk settings. Vancouver (BC): BCCDC; 2019 (Accessed 2019-06-08). http://www. bccdc.ca/resource-gallery/Documents/Guidelines\%20and\%20 Forms/Guidelines\%20and\%20Manuals/Epid/CD\%20Manual/ Chapter\%201\%20-\%20CDC/Enteric\%20Exclusions_Mar\%20 2019.pdf

40. Matussek A, Einemo IM, Jogenfors A, Löfdahl S, Löfgren S. Shiga toxin-producing Escherichia coli in diarrheal stool of Swedish children: evaluation of polymerase chain reaction screening and duration of Shiga toxin shedding. J Pediatric Infect Dis Soc 2016 Jun;5(2):147-51. DOI PubMed

41. Vonberg RP, Höhle M, Aepfelbacher M, Bange FC, Belmar Campos C, Claussen K, Christner M, Cramer JP, Haller H, Hornef M, Fickenscher H, Fraedrich K, Knobloch JK, Kühbacher T, Manns MP, Nitschke M, Peters G, Pulz M, Rohde H, Roseland RT, Sayk F, Schaumburg F, Schöcklmann HO, Schubert S, Solbach W, Karch H, Suerbaum S. Duration of fecal shedding of Shiga toxin-producing Escherichia coli O104:H4 in patients infected during the 2011 outbreak in Germany: a multicenter study. Clin Infect Dis 2013 Apr;56(8):1132-40. DOI PubMed

42. Dabke G, Le Menach A, Black A, Gamblin J, Palmer M, Boxall N, Booth L. Duration of shedding of Verocytotoxin-producing Escherichia coli in children and risk of transmission in childcare facilities in England. Epidemiol Infect 2014 Feb;142(2):327-34. DOI PubMed

43. Galanis E, Taylor M, Romanowski K, Bitzikos O, Jeyes J, Nowakowski C, Stone J, Murti M, Paccagnella A, Forsting S, Li S, Hoang L. Evaluating the timeliness of enteric disease surveillance in British Columbia, Canada, 2012-13. Can J Infect Dis Med Microbiol 2017;2017:9854103. DOl PubMed 